\title{
Left Adrenal Biopsy Using the Convex Curvilinear Ultrasound Scope
}

\author{
Nikhil Meena ${ }^{a, c}$ Cidney Hulett ${ }^{a, c}$ Susanne Jeffus ${ }^{b}$ Thaddeus Bartter ${ }^{a, c}$ \\ Departments of a Medicine and ${ }^{\mathrm{b}}$ Pathology, University of Arkansas for Medical Sciences, and ${ }^{\mathrm{c} C e n t r a l}$ Arkansas \\ Veterans Hospital System, Little Rock, Ark., USA
}

\section{Established Facts}

- Endobronchial ultrasound bronchoscope can be used effectively in the esophagus to assist in the diagnosis and staging of lung cancer and the diagnosis of other benign and malignant conditions.

\section{Novel Insight}

- Endobronchial ultrasound bronchoscope can be used to access and biopsy the left adrenal gland, increasing the diagnostic potential of the pulmonologist.

For editorial comment see p. 17

\section{Key Words}

Lung cancer · Endobronchial ultrasound .

Esophageal ultrasound · Adrenal masses

\section{Abstract}

Effective use of the convex curvilinear ultrasound bronchoscope in the esophagus (EUS-B) is well described. EUS-B has not been described for diagnostic sampling of the left adrenal gland. We describe 6 cases of diagnostic fine-needle aspiration of the left adrenal gland using EUS-B. This capacity increases the diagnostic capabilities of the pulmonologist experienced in EUS-B.

(c) 2014 S. Karger AG, Basel

\section{Introduction}

Endobronchial ultrasound (EBUS) was initially developed for improved access to hilar and mediastinal nodes in the diagnosis and staging of lung cancer. After the technology matured and the convex curvilinear EBUS bronchoscope had been developed, its range of utility was broadened to include the diagnosis of thoracic masses, lymphoma and benign conditions with mediastinal involvement [1-5]. In 2010, two large studies, one by Herth et al. [6] and the other by Hwangbo et al. [7], cemented the validity of use of the EBUS scope both for EBUS and for esophageal ultrasound (EUS-B). This dual use of the EBUS scope gave the interventional pulmonologist

\section{KARGER 125}

E-Mail karger@karger.com www.karger.com/res
C 2014 S. Karger AG, Basel

0025-7931/14/0891-0057\$39.50/0
Dr. Nikhil Meena

University of Arkansas for Medical Sciences

4301 West Markham Mail Slot 555

Little Rock, AR 72205 (USA)

E-Mail nkmeena@uams.edu 


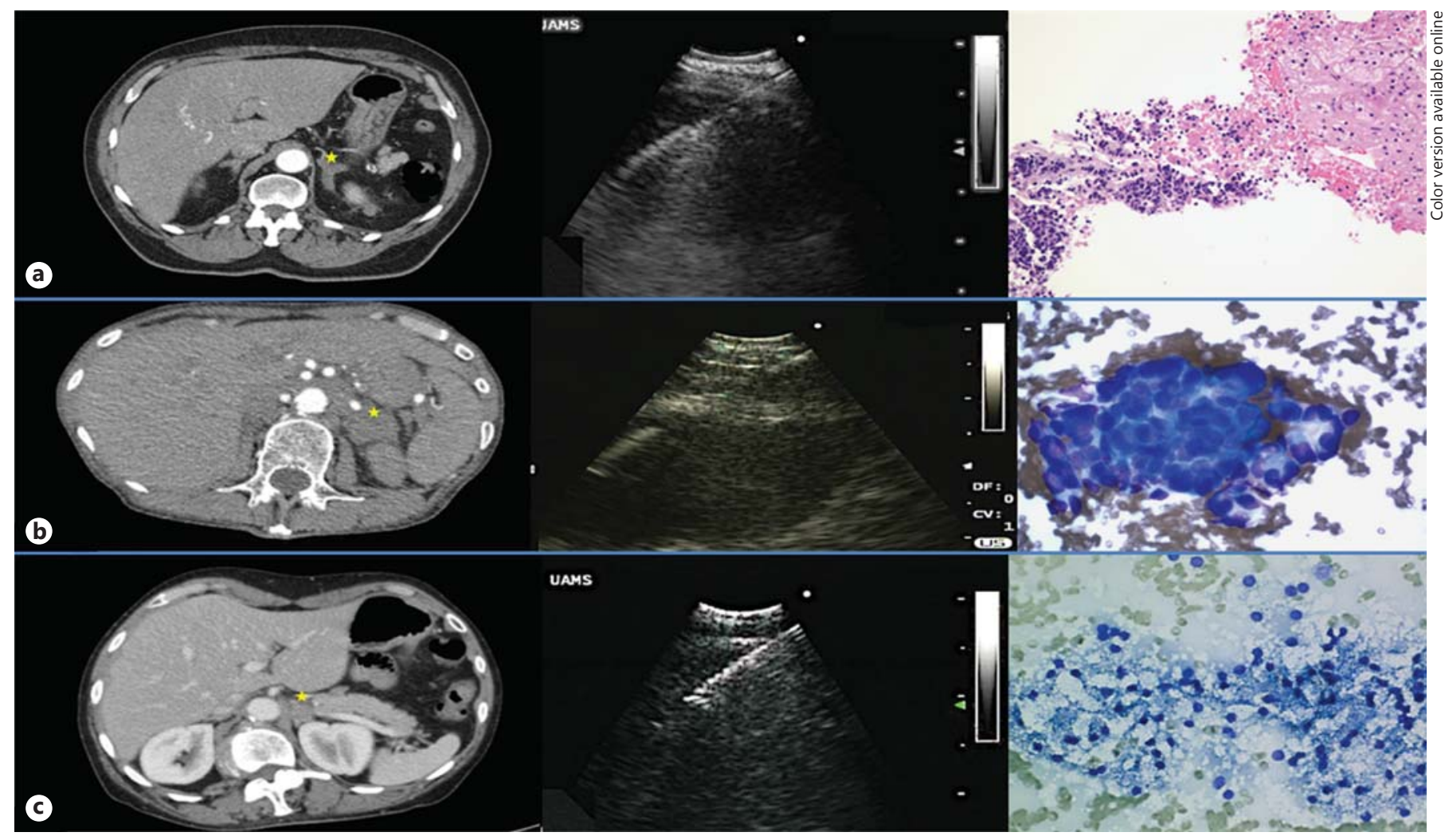

Fig. 1. CT findings, EUS-B visualization of the left adrenal gland, and cytology in 3 of the cases. The approximate site of needle entry into the adrenal gland is marked by a yellow star. a Case 1: the adrenal gland is diffusely enlarged with a maintained 'seagull' configuration; cell block material demonstrates adrenal tissue in the upper right and scattered malignant cells (metastatic small cell carcinoma) in the lower left. $\mathbf{b}$ Case 2 : a $3.3 \times 3.0-\mathrm{cm}$ left adrenal and cytology diagnostic of metastatic adenocarcinoma of pulmonary origin. c Case 3 : a $1.2 \times 1.4-\mathrm{cm}$ adrenal mass and cytology showing a benign adrenal cortical adenoma. broader access to the mediastinum, alternative access to some nodes, and perhaps a greater safety margin for some tenuous patients for whom diagnostic material was paraesophageal [6-11]. We report herein 6 cases that demonstrate a further extension of the utility of EUS-B, access to and fine-needle aspiration (FNA) biopsy of the left adrenal gland. These were consecutive cases of suspected cancer for which left adrenal enlargement had been noted on computed tomographic scan (CT) of the thorax. All had been referred for diagnostic procedures. Three cases were seen at the University of Arkansas for Medical Sciences and 3 were seen at the John L. McClellan Memorial Veterans Hospital.

\section{Case 1}

A 70-year-old male smoker with a history of gunshot wounds to the chest and GERD presented to his gastroenterologist with complaints of chest pain and a 27-lb weight loss. Chest roentgeno- gram demonstrating a lung mass was followed by a chest $\mathrm{CT}$. There was a right hilar mass with interlobar (11R) and subcarinal (7) nodal enlargement (fig. 1a). The left adrenal gland was irregular in shape with the greatest dimensions $1.4 \times 2.7 \mathrm{~cm}$. Because of the staging implications, diagnostic work-up was begun with EUS-B looking for the left adrenal gland rather than for station 7. The adrenal gland was visualized, and FNA material was obtained. Smears for rapid on-site cytologic evaluation (ROSE) were read by a cytopathologist as positive for malignancy. Cell block analysis, including immunohistochemistry, led to a final diagnosis of metastatic small cell carcinoma.

\section{Case 2}

A 71-year-old woman with ongoing weight loss was being followed for a chest mass formerly reported to have been biopsy negative. When the mass enlarged, she was referred to interventional pulmonology. A CT of the chest at that time showed a large left upper lobe mass encasing the left pulmonary artery. The left adrenal measured $3.3 \times 3.0 \mathrm{~cm}$ (fig. $1 \mathrm{~b}$ ). The patient was short of breath at rest and only EUS-B was performed, starting 
with the left adrenal gland. The adrenal was visualized and FNA material was positive for malignancy on ROSE. Tissue submitted for cell block showed tumor cells which were strongly and diffusely positive for TTF-1 by immunohistochemistry, supporting the diagnosis of a metastatic adenocarcinoma of pulmonary origin.

\section{Case 3}

A 60-year-old woman with a history of tobacco and illicit drug use presented to the emergency room with complaints of chest pain and dizziness following a fall. CT of the head was normal, while $\mathrm{CT}$ of the chest demonstrated a right upper lobe mass with nodal enlargement of stations $4 \mathrm{R}$ and $11 \mathrm{R}$. Her left adrenal gland contained a small mass that measured $1.4 \times 1.2 \mathrm{~cm}$ (fig. 1c). Due to its potential implications, the adrenal was approached first with EUS-B. FNA was performed, and the cytopathologist performing ROSE read the smear as negative for carcinoma. The findings were consistent with an adrenal cortical adenoma. The $4 \mathrm{R}$ node was then biopsied and was positive for squamous cell carcinoma. Subsequent adrenal cell block analysis confirmed the finding of a benign adrenal adenoma.

\section{Case 4}

A 73-year-old male smoker with a past medical history of congestive heart failure and chronic obstructive pulmonary disease presented with a 3 -week history of right shoulder pain and cough with purulent sputum. CT of the chest demonstrated a large right upper lobe mass with suspect right hilar nodes. In the abdomen the left adrenal gland was enlarged, measuring $3.3 \times 2.4 \mathrm{~cm}$. Given the adrenal enlargement, EUS-B was performed first. The adrenal was visualized and FNA material was positive for a metastatic poorly differentiated carcinoma. Cell block material was positive by immunohistochemistry for $\mathrm{CK} 7$ and negative for TTF-1, CK 20, CK 5/6, p63 and inhibin. The CT findings coupled with the cytologic and immunohistochemical findings led to a diagnosis of poorly differentiated stage IV non-small cell lung cancer.

\section{Case 5}

A 64-year-old man had undergone right upper lobectomy for lung cancer in 2007. A follow-up CT of the chest in 2014 showed mass/adenopathy in the paraesophageal area corresponding to the station 7 position. In addition, there was a $2.4 \times 2.0-\mathrm{cm}$ left adrenal mass. On EUS-B the paraesophageal mass was located and FNA material was positive for malignancy. The stomach was then entered, and the adrenal gland was visualized and sampled, with ROSE also positive for malignancy. Upon analysis, both cell blocks contained tumor cells which were morphologically similar, resulting in diagnosis of a metastatic adenocarcinoma. The cells were also morphologically similar to those from the lobectomy of 7 years earlier.

Left Adrenal Biopsy Using the Convex

Curvilinear Ultrasound Scope

\section{Case 6}

A 62-year-old man with a 50-pack-year smoking history and past medical history of atherosclerotic vascular disease presented with hoarseness and was found to have left true vocal cord paralysis. Chest CT demonstrated a left upper lobe mass and left hilar and station $4 \mathrm{~L}$ adenopathy. CT of the abdomen demonstrated a $5.1 \times 4.4-\mathrm{cm}$ left adrenal mass. EUS-B was performed, beginning with the adrenal mass. FNA material from the left adrenal gland was positive for a metastatic poorly differentiated non-small cell carcinoma.

\section{Discussion}

The adrenal glands are a relatively common site of metastasis and represent the fourth most common site of metastasis for lung cancer $[12,13]$. The percentage of lung cancer patients with adrenal metastases varies with clinical circumstances. Whereas on autopsy approximately one third of lung cancer patients will be found to have adrenal metastases, at the time of initial evaluation the incidence of patients with adrenal metastases appears to be in the range of 1.6-4\% [14-16]. Benign adrenal adenomas are relatively common; adrenal masses will be found in $4-10 \%$ of patients with non-small cell lung cancer undergoing evaluation, and the majority of those masses will be benign [14-16]. Noninvasive diagnosis can be problematic; CT, MRI and PET each has pitfalls, even when used in conjunction with each other [16-18]. An adrenal biopsy positive for metastatic cancer, on the other hand, definitively establishes stage IV disease.

The left adrenal gland is the more common site of adrenal metastasis $[15,17]$ and is almost always accessible from the stomach [18-20]. Several studies have looked at the use of esophageal ultrasound-guided FNA for the diagnosis of left adrenal lesions [18-20]. These studies have demonstrated tissue adequacy in the $94-100 \%$ range and a safety profile superior to that of either CT-guided biopsy or transcutaneous ultrasoundguided biopsy. Reasons for the increased safety margin when EUS is compared with transcutaneous approaches are relatively intuitive; with EUS, the operator is closer to the adrenal gland, is not at risk of crossing the pleural space, and can avoid the pancreas and local vasculature with magnified real-time imaging [18]. Interestingly, one of the three cited studies was performed by pulmonologists who had been trained in the use of the EUS scope traditionally used by gastroenterologists [20]. 
Our series is the first report that we are aware of demonstrating that the adrenal gland is accessible using the convex curvilinear bronchoscope for esophageal access (EUS-B). In all cases in this series, a cell block large enough for additional studies, such as immunohistochemistry, was generated from the adrenal material. The utility of EUS-B has been well documented [6-10], but left adrenal access using EUS-B has not. Access to the left adrenal gland increases the capacity of the pulmonologist skilled in EUS-B to both diagnose and stage a lung cancer patient using one scope and one procedural sedation. All cases in this series were performed using an Olympus EBUS scope (BC-UC180F, Olympus Medical Supply Corporation, Tokyo, Japan) under conscious sedation (midazolam plus fentanyl in 3 cases and propofol in 3 cases). Patient positioning for left adrenal biopsy was our standard positioning for EBUS and for EUS-B; the patient is supine on a stretcher with the head of the stretcher elevated to about thirty degrees. Neither esophageal insufflation nor the saline-filled EBUS balloon was used for any biopsy. All FNAs were performed using the Olympus 22-gauge needle designed for use with the EBUS scope. ROSE was available at every procedure.

This is not a head-to-head comparison with the EUS scope. The EUS scope has a wider field of view and a greater depth of view [11]. It is also more rigid, a factor that may facilitate visualization of the adrenal gland from the stomach; unlike the airways and esophagus, the stomach does not 'channel' the scope. Because of these attributes, we suspect that in a head-to-head comparison of EUS-B versus EUS for left adrenal biopsy, the EUS scope might be shown to be superior. We would also note that in this study we sought to visualize and sample only those left adrenal glands with enlargement (diameters from 1.2 to $5.5 \mathrm{~cm}$ ) visible on CT. Nevertheless, we have demonstrated that operators comfortable with the EBUS scope in both the airway and the esophagus can actively seek and successfully biopsy the left adrenal gland when it is enlarged, and can thereby add to the diagnostic value of the procedure.

In summary, this series of six consecutive diagnostic left adrenal biopsies is the second series showing that pulmonologists can access and biopsy the left adrenal gland [20] and the first showing that they can do it using the convex curvilinear ultrasound bronchoscope (EUS-B). While the EUS scope may be superior for left adrenal biopsy, this does not negate the fact that experienced interventional pulmonologists can at times easily and efficiently increase the diagnostic value of their procedures by using EUS-B to biopsy the left adrenal gland. A multi-institution trial would help to understand in more detail to what degree these results can be generalized.

\section{Financial Disclosure and Conflicts of Interest}

All authors were involved in the procedures, analysis of data and writing of the manuscript. The authors have no conflicts of interest with respect to the content of the manuscript.

\section{References}

$>1$ Tournoy KG, Rintoul RC, van Meerbeeck JP, Carroll NR, Praet M, Buttery RC, et al: EBUS-TBNA for the diagnosis of central parenchymal lung lesions not visible at routine bronchoscopy. Lung Cancer 2009;63: 45-49.

$>2$ Oguri T, Imai N, Imaizumi K, Elshazley M, Hashimoto I, Hashimoto N, et al: Febrile complications after endobronchial ultrasound-guided transbronchial needle aspiration for intra-pulmonary mass lesions of lung cancer - a series of 3 cases. Respir Investig 2012;50:162-165

$>3$ Steinfort DP, Conron M, Tsui A, Pasricha SR, Renwick WE, Antippa P, et al: Endobronchial ultrasound-guided transbronchial needle aspiration for the evaluation of suspected lymphoma. J Thorac Oncol 2010;5:804-809.

4 Wong M, Yasufuku K, Nakajima T, Herth FJ, Sekine Y, Shibuya K, et al: Endobronchi- al ultrasound: new insight for the diagnosis of sarcoidosis. Eur Respir J 2007;29:11821186.

5 Garwood S, Judson MA, Silvestri G, Hoda R, Fraig M, Doelken P: Endobronchial ultrasound for the diagnosis of pulmonary sarcoidosis. Chest 2007;132:1298-1304.

-6 Herth FJ, Krasnik M, Kahn N, Eberhardt R, Ernst A: Combined endoscopic-endobronchial ultrasound-guided fine-needle aspiration of mediastinal lymph nodes through a single bronchoscope in 150 patients with suspected lung cancer. Chest 2010;138:790794.

7 Hwangbo B, Lee GK, Lee HS, Lim KY, Lee SH, Kim HY, et al: Transbronchial and transesophageal fine-needle aspiration using an ultrasound bronchoscope in mediastinal staging of potentially operable lung cancer. Chest 2010;138:795-802.
8 Hwangbo B, Lee HS, Lee GK, Lim KY, Lee SH, Kim HY, et al: Transoesophageal needle aspiration using a convex probe ultrasonic bronchoscope. Respirology 2009;14:843-849.

$\checkmark 9$ Abouzgheib W, Nahra R, Homsi S, Bartter T: Safety and feasibility of identifying and sampling of mediastinal structures through the esophagus using EBUS. Chest 2009; 136(suppl): 110 .

10 Abouzgheib W, Shweihat Y, Bartter T: Oesophageal applications of the convex curvilinear ultrasound bronchoscope: an illustrative case series. Respirology 2011;16:965968

11 Annema JT, Rabe KF: Endosonography for lung cancer staging: one scope fits all? Chest 2010;138:765-767.

-12 Abrams HL, Spiro R, Goldstein N: Metastases in carcinoma: analysis of 1,000 autopsied cases. Cancer 1950;3:74-85. 
13 Quint LE, Tummala S, Brisson LJ, Francis IR, Krupnick AS, Kazerooni EA, et al: Distribution of distant metastases from newly diagnosed non-small cell lung cancer. Ann Thorac Surg 1996;62:246-250.

14 Oliver TW Jr, Bernardino ME, Miller JI, Mansour K, Greene D, Davis WA: Isolated adrenal masses in non-small cell bronchogenic carcinoma. Radiology 1984;153:217-218.

15 Ettinghausen SE, Burt ME: Prospective evaluation of unilateral adrenal masses in patients with operable non-small-cell lung cancer. J Clin Oncol 1991;9:1462-1466.
6 Porte HL, Ernst OJ, Delebecq T, Metois D, Lemaitre LG, Wurtz AJ: Is computed tomography guided biopsy still necessary for the diagnosis of adrenal masses in patients with resectable non-small-cell lung cancer? Eur J Cardiothorac Surg 1999;15:597-601.

17 Kim JY, Kim SH, Lee HJ, Kim MJ, Kim YH, Cho $\mathrm{SH}$, et al: Utilisation of combined $\mathrm{F}$ ${ }^{18}$ FDG PET/CT scan for differential diagnosis between benign and malignant adrenal enlargement. Br J Radiol 2013;86:20130190.

18 Eloubeidi MA, Seewald S, Tamhane A, Brand B, Chen VK, Yasuda I, et al: EUS-guided FNA of the left adrenal gland in patients with thoracic or GI malignancies. Gastrointest Endosc 2004;59:627-633.
9 Bodtger U, Vilmann P, Clementsen P, Galvis E, Bach K, Guldhammer B: Clinical impact of endoscopic ultrasound-fine needle aspiration of left adrenal masses in established or suspected lung cancer. J Thorac Oncol 2009;4: 1485-1489.

20 Schuurbiers OC, Tournoy KG, Schoppers HJ, Dijkman BG, Timmers HJ, de Geus-Oei LF, et al: EUS-FNA for the detection of left adrenal metastasis in patients with lung cancer. Lung Cancer 2011;73:310-315. 